\title{
The Formation of Abscesses in the Peritoneal Cavity and the Left Internal Obturator Muscle as the Complications of the Transobturator Tape Procedure
}

\section{Sang-Min Shim, Min-Gyeong Jo, Yun-Sook Kim}

Department of Obstetrics and Gynecology, Soonchunhyang University Cheonan Hospital, Soonchunhyang University College of Medicine, Cheonan, Korea

\begin{abstract}
The synthetic, tension-free midurethral sling procedure using transobturator tape (TOT) was introduced in 2001. Since then, it has become a mainstream modality in patients with stress urinary incontinence. But, it has been reported to produce many complications such as mesh erosion, hematoma formation, and abscess. We experienced a case of abscess formation in the peritoneal cavity and left internal obturator muscle seven days after the TOT sling procedure, for which we performed a complete removal of mesh and a percutaneous drainage of the peritoneal abscess using 10.2-F drain-fix at the department of interventional radiology. To our knowledge, our case is one of the serious complications of the TOT procedure. Here, we report our case with a review of literatures.
\end{abstract}

Keywords: Abscess; Stress urinary incontinence; Suburethral slings

\section{INTRODUCTION}

Stress urinary incontinence (SUI) is a common condition that affects women's quality of life. A novel minimally invasive procedure, the transobturator tape (TOT) technique, was developed. Since then, the surgical treatment using the TOT has been considered a safe, effective method for treating patients with SUI [1]. Although patients undergoing TOT procedure are followed up for short periods of time, they are known to present with postoperative complications such as vulva hematoma, urinary retention, de novo urgency, vaginal erosion or abscess formation. This deserves special attention from clinicians [2]. We experienced a case of abscess formation in peritoneal cavity and the left internal obturator muscle seven days after the TOT sling procedure. Here, we report our case with a review of literatures.

\section{CASE REPORT}

A 52-year-old woman presented to emergency department complaining of a 1 week history of lower abdominal pain, fever, and increased pain in both thighs and groins. The patient had ten- der and swollen groins. Ten days before visiting us, the patient underwent TOT procedure at a local clinic. In addition, 2 days before visiting us, the patient underwent complete removal of the suburethral polypropylene mesh at the same local clinic. Nevertheless, the patient had aggravation of pain in both thighs.

On physical examination and serum biochemistry, the patient had a temperature of $38^{\circ} \mathrm{C}$, and serum C-reactive protein levels of $411.9 \mathrm{mg} / \mathrm{L}$ (normal range, 0.01 to $3.0 \mathrm{mg} / \mathrm{L}$ ). In addition, the patient had a $100 \times 46 \mathrm{~mm}$ sized peritoneal abscess and a $38 \times 23 \mathrm{~mm}$ sized abscess in the left internal obturator muscle, accompanied by gas-forming bacterial infections, on abdominal and pelvic computed tomography (APCT) scans (Fig. 1). The patient was given an intravenous administration of antibiotics such as ceftizoxime and metronidazole because of anerobes empirically. On day 2, the patient had a temperature of $39.6^{\circ} \mathrm{C}$ and a chill, accompanied by aggravation of pain in both inguinal regions. On vaginal examination, the patient had a pus discharge at the sites of incision on the anterior vaginal wall. Therefore, the patient underwent percutaneous peritoneal abscess drainage using a 10.2-F drain-fix at the department of interventional radiology (Fig. 2). Approximately total $260 \mathrm{~mL}$ of yellowish pus was drained for 14 days. On bacterial cul-
Correspondence to: Yun-Sook Kim

Department of Obstetrics and Gynecology, Soonchunhyang University Cheonan Hospital, Soonchunhyang University College of Medicine,

31 Suncheonhyang 6-gil, Dongnam-gu, Cheonan 330-930, Korea

Tel: +82-41-570-2150, Fax: +82-41-571-7887, E-mail: drsook@schmc.ac.kr

Received: May 8, 2014 / Accepted after revision: Jun. 10, 2014
(C) 2014 Soonchunhyang Medical Research Institute This is an Open Access article distributed under the terms of the Creative Commons Attribution Non-Commercial License (http://creativecommons.org/licenses/by-nc/3.0/). 


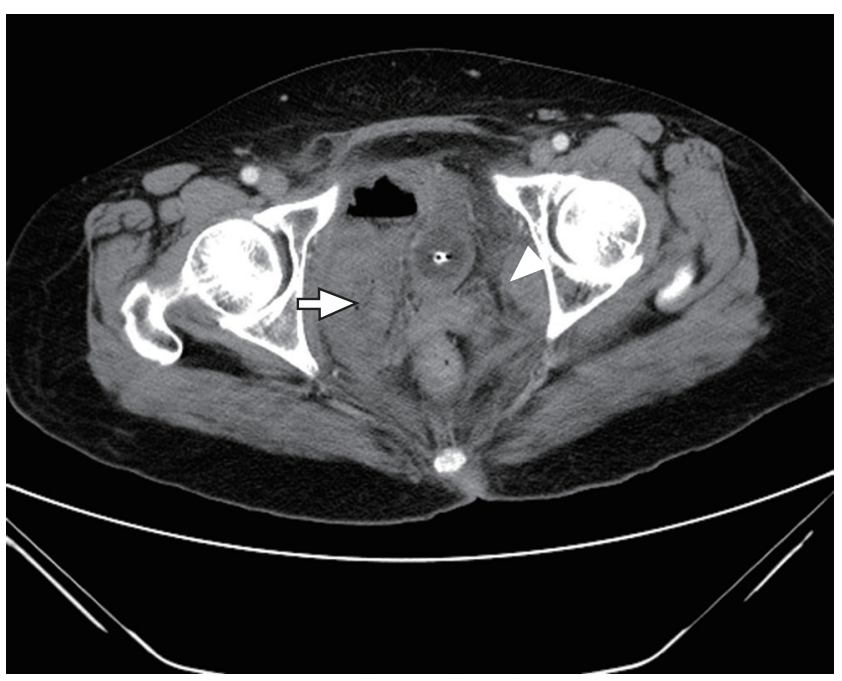

Fig. 1. Abdominal and pelvic computed tomography scans. The patient had $100 \times 46 \mathrm{~mm}$ sized peritoneal abscess (arrow) and $38 \times 23 \mathrm{~mm}$ sized abscess in the left internal obturator muscle (arrow head), accompanied by gas-forming bacterial infections.

ture test, gram positive Streptococcus constellatus was identified. On day 14 , the patient had a drain removed before discharge. Two months thereafter, the patient achieved spontaneous closure of the incision site on the anterior vaginal wall, and showed no recurrent episodes.

\section{DISCUSSION}

As compared with the tension-free vaginal tape procedure, the TOT has been considered to produce less complications such as bladder perforation, or pelvic hematoma. But there are some reports about foreign body reactions due to synthetic slings, such as erosions or infections [3]. Peritoneal and obturator abscess occur as complications of the suburethral sling surgery possibly due to the anatomical route of the TOT along the obturator fossa. Moreover, there are also other reports about obturator muscle abscesses occurring within few days after the TOT [4,5], or up to 2 or 3 years postoperatively [6]. In the current cases, the patient had an abscess in the left internal obturator muscle three days after the TOT procedure. We performed an APCT and an ultrasonography to confirm the presence of the abscess. It is generally known, however, that a magnetic resonance imaging is a more accurate diagnostic modality for assessing the extent of infection [7]. In most of the patients who suspected of having an abscess in the thigh or obturator muscles after the TOT procedure, clinicians should carefully examine the vagina because the abscess formation is followed by

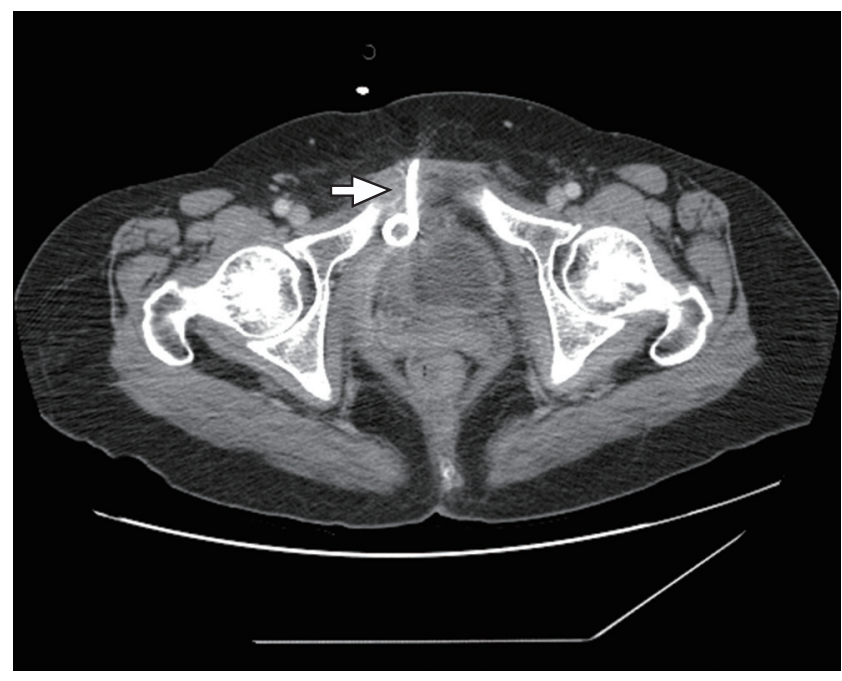

Fig. 2. Percutaneous drainage of the peritoneal abscess. On vaginal examination, the patient had a pus discharge at the sites of incision on the anterior vaginal wall. Therefore, the patient underwent percutaneous peritoneal abscess drainage using 10.2-F drain-fix (arrow) at the department of interventional radiology.

the erosion of TOT. In these cases, a complete removal of mesh is essential for preventing the recurrences of infections. In case of large peritoneal abscess, it would be undesirable to perform the additional conservative management with the sole use of intravenous antibiotics. Moreover, clinicians should consider immediate drainage of abscess using a percutaneous catheter guided incision in patient who had abscess formation. We therefore the peritoneal abscess using a 10.2-F percutaneous drain-fix at the department of interventional radiology. This was less painful for the patient. Placement of the percutaneous drainage catheters has been considered the first-line of therapy patients with peritoneal abscesses. It is useful to avoid surgical intervention or to improve surgical outcomes [8]. In addition, we immediately removed the implanted tape and abscess drain. To our knowledge, our case is one of the serious complications of the TOT procedure. Here, we report our case with a review of literatures.

\section{ACKNOWLEDGMENTS}

This work was supported in part by the Soonchunhyang University Research Fund.

\section{REFERENCES}

1. Song CH, Son YJ. Surgical results of stress incontinence treated by trans- 
obturator tape (TOT): clinical analysis of 80 cases. Korean J Obstet Gynecol 2006;49:1326-31.

2. Kim CH, Cho MK, Kim JW, Kim SM, Kim YH, Oh ST, et al. Clinical study of complications in the surgical management of stress urinary incontinence using transobturator tape (TOT). Korean J Obstet Gynecol 2008;51:1011-7.

3. Garcia SL, Ramirez DL, Rey JR, Calvo JF, Iglesias BR, Calvo AO. Complications of polypropylene mesh for the treatment of female pelvic floor disorders. Arch Esp Urol 2011;64:620-8.

4. Kim YW, Kim SM, Kim WT, Kim YJ, Yun SJ, Lee SC, et al. Acute and serious myositis with abscess in thigh muscle after transobturator tape im- plantation. Int Neurourol J 2010;14:182-5.

5. Leanza V, Garozzo V, Accardi M, Molino A, Conca M, Basile A. A late complication of transobturator tape: abscess and myositis. Minerva Ginecol 2008;60:91-4.

6. Lee SY, Kim JY, Park SJ, Kwon YW, Nguyen HB, Chang IH, et al. Bilateral recurrent thigh abscesses for five years after a transobturator tape implantation for stress urinary incontinence. Korean J Urol 2010;51:657-9.

7. Yang JM, Yang SH, Huang WC. Dynamic interaction involved in the tension-free vaginal tape obturator procedure. J Urol 2008;180:2081-7.

8. Park J, Charles HW. Intra-abdominal abscess drainage: interval to surgery. Semin Intervent Radiol 2012;29:311-3. 